\title{
Dampak Program Keluarga Harapan (PKH) terhadap Kesejahteraan Keluarga di Desa Padang Seurahet Kecamatan Johan Pahlawan Kabupaten Aceh Barat
}

\author{
Lia Muliana ${ }^{1}$, Mursyidin ${ }^{1}$, Muharriyanti Siregar ${ }^{2}$ \\ ${ }^{1}$ Fakultas Ilmu Sosial dan Ilmu Politik, Universitas Malikussaleh, Aceh Utara, 24351, Indonesia. \\ ${ }^{2}$ Fakultas Ekonomi, Universitas Teuku Umar, Meulaboh, 23661, Indonesia
}

\begin{tabular}{|c|c|}
\hline ARTICLE INFORMATION & A B S T R A C T \\
\hline Received: April 13, 2021 & \multirow{9}{*}{$\begin{array}{l}\text { The Family Hope Program (PKH) is a conditional cash transfer program for low-income families. The } \\
\text { requirement is to be actively involved in education and health. The Family Hope Program in Indonesia was } \\
\text { implemented in } 2007 \text { to alleviate poverty and prosper low-income families. The research and writing of this } \\
\text { journal aim to determine the impact of PKH on family welfare and see if there is a reduction in poverty after } \\
\text { the government realizes the Family Hope Program. This study uses a qualitative method with a descriptive } \\
\text { approach. The study results indicate that the impact of PKH on beneficiary families, including the cash } \\
\text { provided, can meet consumption or family needs and help the economy of PKH recipient families. The } \\
\text { implementation of the program can reduce poverty in Aceh. The percentage of the poverty rate fell to } 0.02 \% \text {. The } \\
\text { limitation of the research is the impact of PKH on family welfare and wants to examine whether there is a } \\
\text { decrease in the percentage of poverty in Aceh or Aceh Barat. The practical implication of this research is to } \\
\text { provide information to the government that PKH can improve the welfare of low-income families. The socia } \\
\text { significance is to give the government and the general public that the implementation of social assistance } \\
\text { programs, one of which is the Family Hope Program, can reduce poverty rates in Aceh or West Aceh. The } \\
\text { originality of the research is supported by previous research related to the author's research study. }\end{array}$} \\
\hline Revised: May 04, 2021 & \\
\hline Accepted: October 20, 2021 & \\
\hline Available online: October 28, 2021 & \\
\hline KEYWORDS & \\
\hline $\begin{array}{l}\text { Family Hope Program (PKH), Family Welfare, Social } \\
\text { Change }\end{array}$ & \\
\hline CORRESPONDENCE & \\
\hline Name: Mursyidin & \\
\hline E-mail: mursyidinza@unimal.ac.id & \\
\hline
\end{tabular}

\section{PENDAHULUAN}

Negara berkembang memiliki banyak permasalahanpermasalahan di dalam pemerintahannya, baik itu permasalahan sosial, ekonomi, budaya, politik, dan lain sebagainya. Seperti Negara Indonesia yang merupakan negara berkembang yang tidak luput dari namanya konflik, kericuhan, dan masalah sosial ekonomi, yaitu kemiskinan. Indonesia merupakan negara yang masih tingginya angka kemiskinan. Permasalahan kemiskinan selalu menjadi pusat perhatian utama bagi pemerintah Indonesia untuk di tanggulangi agar angka kemiskinan di Indonesia menurun dan dapat mensejahterakan keluarga miskin.

Periode pemerintahan saat ini adalah masa pemerintahan Jokowi Dodo, semenjak pemerintahan Jokowi, ada beberapa program bantuan sosial yang diluncurkan dengan tujuan untuk mengurangi angka kemiskinan dan meningkatkan kualitas sumber daya manusia. Misalnya Program Keluarga Harapan (PKH), Kartu Indonesia Pintar (KIP), Kartu Keluarga Sejahtera (KKS), dan program bantuan sosial lainnya.

Program bantuan sosial yang dikemukakan oleh pemerintah dalam rangka penanggulangan kemiskinan berbasis rumah tangga, pemerintah meluncurkan program khusus yang diberi nama "Program Keluarga Harapan (PKH)". Program ini pertama kali diluncurkan di Indonesia pada tahun 2007.

Program Keluarga Harapan adalah program pemberian uang tunai kepada Rumah Tangga Sangat Miskin (RTSM) berdasarkan persyaratan dan ketentuan yang telah ditetapkan dengan melaksanakan kewajibannya. Program semacam ini secara internasional dikenal sebagai program conditional cash transfers (CCT) atau Program Bantuan Tunai Bersyarat. Persyaratan tersebut dapat berupa kehadiran di fasilitas pendidikan misalnya bagi anak usia sekolah, ataupun kehadiran di fasilitas kesehatan misalnya bagi anak balita dan bagi ibu hamil (Pancawangi, 2019).

Program Keluarga Harapan ditujukan kepada keluarga fakir miskin yang memenuhi syarat sebagai peserta penerima bantuan sosial PKH. Peluncuran program ini sebagai wujud kinerja dan partisipasi pemerintah dalam mengentaskan kemiskinan, mewujudkan masyarakat yang sejahtera, memberdayakan masyarakat dapat terealisasikan di dalam keluarga melalui program bantuan sosial ini.

Untuk mendukung penelitian dan penulisan jurnal ini, penulis menyajikan beberapa hasil riset sebelumnya yang berkaitan dengan pokok pembahasan kajian penelitian penulis. Adapun hasil riset sebelumnya mengemukakan bahwasanya Program Keluarga Harapan berdampak terhadap kesejahteraan keluarga penerima PKH. Sebagaimana penelitian yang dilakukan oleh Winda Jayanti mengenai "Pengaruh Program Keluarga Harapan terhadap kesejahteraan keluarga di Desa Pasar X Kecamatan Kutalimbaru Kabupaten Deli Serdang”. Hasil penelitian menunjukkan bahwa adanya pengaruh antara Program Keluarga Harapan terhadap kesejahteraan keluarga (Jayanti, 2018).

Kajian lainnya juga dilakukan oleh Tri Cahyono mengenai "Kontribusi PKH terhadap kesejahteraan keluarga penerima manfaat”. Hasil penelitiannya adalah Program Keluarga Harapan berkontribusi kepada peningkatan kesejahteraan keluarga, khususnya mereduksi kekurangan kualitas dan kuantitas pangan, kesehatan, dan pendidikan, sehingga keluarga penerima manfaat PKH cenderung lebih sejahtera (Cahyono, 2018). 
Perbedaan penelitian terdahulu dengan penelitian penulis yaitu terletak pada lokasi penelitian yang dilakukan, metode penelitian, dan fokus penelitian Cahyono tidak hanya mengamati bantuan sosial PKH sangat berkontribusi dalam pemenuhan konsumsi, melainkan juga melihat aspek kesehatan dan pendidikan. Sedangkan penelitian penulis hanya memfokuskan program PKH berdampak terhadap kesejahteraan keluarga penerima manfaat program, dan membantu ekonomi rumah tangga.

Pertanyaan dalam penelitian ini adalah apakah Program Keluarga Harapan berdampak terhadap kesejahteraan keluarga dan apakah ada penurunan presentase angka kemiskinan di Aceh atau Aceh Barat. Dengan mengkaji kedua hal berikut ini, sehingga penelitian ini bertujuan untuk mengetahui dampak Program Keluarga Harapan terhadap kesejahteraan keluarga dan dapat mengetahui apakah ada penurunan angka kemiskinan di Aceh atau Aceh Barat setelah pemerintah meluncurkan program bantuan sosial, salah satunya Program Keluarga Harapan (PKH).

Dalam mengkaji dan menganalisis fenomena ini, penulis menggunakan teori perubahan sosial Piotr Sztompka. Menurut Farley (dalam buku Sztompka, 2004: 5), perubahan sosial adalah perubahan pola perilaku, hubungan sosial, lembaga, dan struktur sosial pada waktu tertentu. Perubahan sosial dapat dibayangkan terjadi pada tingkat makro seperti sistem internasional, bangsa, dan negara. Perubahan dapat juga terjadi pada tingkat mezo seperti pada perusahaan, partai politik, gerakan keagamaan, dan asosiasi besar, serta terjadi pada tingkat mikro seperti keluarga, komunitas, kelompok pekerjaan, dan lingkungan pertemanan (Sztompka, 2004: 5). Dalam perubahan sosial yang dikemukakan Sztompka, membahas mengenai dimensi waktu, bahwasanya perubahan sosial itu mencakup adanya perbedaan antara masa lalu, masa kini, dan masa mendatang (Sztompka, 2004: 45).

\section{METODE}

Pengamatan ini dilakukan menggunakan metode kualitatif dengan pendekatan deskriptif. Metode kualitatif adalah metode penelitian yang digunakan untuk meneliti pada kondisi obyek yang alamiah (sebagai lawannya adalah eksperimen), dimana peneliti adalah sebagai instrumen kunci, teknik pengumpulan data dilakukan secara trianggulasi (gabungan), analisis data bersifat induktif, dan hasil kualitatif lebih menekankan makna dari pada generalisasi (Sugiyono, 2014).

Penelitian dilakukan di Desa Padang Seurahet yang merupakan salah satu desa di Kecamatan Johan Pahlawan Kabupaten Aceh Barat yang menerima bantuan Program Keluarga Harapan. Mayoritas mata pencaharian masyarakat Padang Seurahet adalah nelayan, dan keluarga nelayan dikategorikan sebagai keluarga miskin, dikarenakan penghasilannya sangat begantung kepada cuaca atau iklim laut. Adapun informan dalam penelitian penulis yaitu keluarga penerima manfaat Program Keluarga Harapan.

Pengumpulan data dilakukan dengan observasi terkait realitas yang dikaji pada konteks sosial. Observasi tersebut berfokus pada keluarga PKH dan dilakukan secara intensif, wawancara langsung dengan keluarga penerima PKH agar mendapat informasi yang valid dan akurat, serta dokumentasi. Analisis data dilakukan dengan reduksi data atau memilah hal yang penting, kemudian penulis memberikan coding atau kode, selanjutnya melakukan display data atau penyajian data, dan tahap terakhir adalah penarikan kesimpulan penelitian

\section{HASIL DAN PEMBAHASAN}

\section{Dampak Program Keluarga Harapan Terhadap Kesejahteraan Keluarga Penerima PKH Di Desa Padang Seurahet.}

Program Keluarga Harapan adalah program penanggulangan kemiskinan dan kedudukan PKH merupakan bagian dari program-program penanggulangan kemiskinan lainnya. Program Keluarga Harapan memberikan bantuan tunai kepada Rumah Tangga Sangat Miskin (RTSM), jika mereka memenuhi persyaratan yang terkait dengan upaya peningkatan kualitas hidup dalam bidang kesehatan dan pendidikan (Utomo, 2012).

Program Keluarga Harapan di Indonesia mulai dilaksanakan pada tahun 2007 dan diharapkan dapat dilaksanakan secara berkesinambungan. PKH bertujuan mengurangi beban RTSM dan diharapkan dapat memutus mata rantai kemiskinan antar generasi, sehingga generasi berikutnya dapat keluar dari kemiskinan (Virgoreta, 2014).

$\mathrm{PKH}$ juga mendukung pencapaian tujuan pembangunan Millenium Development Goals (MDGs). Program ini dikenal sebagai Program Bantuan Tunai Bersyarat. Persyaratan tersebut berupa kehadiran di fasilitas pendidikan yaitu anak usia sekolah, maupun kehadiran di fasilitas kesehatan yaitu anak balita dan ibu hamil (Cermati, 2016).

Adapun kriteria peserta penerima PKH (Prasasti, 2017) yaitu:

a. Ibu hamil/nifas/anak balita.

b. Anak pra sekolah/belum masuk pendidikan dasar (usia 5-7 tahun).

c. Anak sekolah SD/MI/Paket A/SDLB (usia 7-12 tahun).

d. Anak sekolah SLTP/MTs/Paket B/SMLB (usia 12-15 tahun).

e. Anak usia 15-18 tahun yang belum menyelesaikan pendidikan dasar.

Bantuan uang tunai PKH diberikan kepada ibu atau perempuan dewasa (nenek, bibi, atau kakak perempuan) yang disebut Pengurus Keluarga. Uang yang diberikan kepada pengurus keluarga lebih efektif meningkatkan kuallitas pendidikan dan kesehatan. Apabila tidak ada perempuan dewasa dalam keluarga maka digantikan kepala keluarga. Keluarga yang telah ditetapkan sebagai penerima PKH akan mendapatkan haknya sebagai berikut:

a. Menerima bantuan uang tunai

b. Menerima pelayanan kesehatan (ibu dan bayi) di Puskesmas, Posyandu, Polindes, sesuai ketentuan yang berlaku.

c. Menerima pelayanan pendidikan (anak usia wajib belajar Pendidikan Dasar 9 tahun).

Selain itu, peserta PKH diwajibkan memenuhi persyaratan dalam kegiatan pendidikan anak dan kesehatan keluarga (ibu dan anak) yaitu:

\section{Kesehatan}

Peserta PKH diwajibkan memenuhi persyaratan kesehatan sebagai berikut:

a. Bayi baru lahir (BBL) harus mendapat IMD, pemeriksaan segera saat lahir, Vitamin K, HBO, salep mata, dan konseling menyusui. 
b. Anak usia 0-28 hari harus diperiksa 3 kali, pertama 6-48 jam, kedua 3-7 hari, dan ketiga 8-28 hari.

c. Anak usia 0-6 bulan harus diberikan ASI eksklusif.

d. Anak usia 0-1l bulan harus diimunisasi lengkap (BCG, DPT, Polio, Campak, Hepatitis B) dan ditimbang secara rutin setiap bulan.

e. Anak usia 6-11 bulan harus mendapatkan Vitamin A sebanyak 2 kali dalam setahun (Februari dan Agustus).

f. Anak usia 12-59 bulan harus mendapatkan imunisasi tambahan dan ditimbang secara rutin setiap bulan.

g. Anak usai 5-6 tahun harus ditimbang secara rutin setiap bulan dan mengikuti program Pendidikan Anak Usia Dini (PAUD) apabila di Posyandu terdekat terdapat PAUD.

h. Ibu hamil harus melakukan pemeriksaan sebanyak 4 kali, pertama pada usia kehamilan 0-3 bulan, kedua pada usia kehamilan 4-6 bulan, ketiga pada kehamilan 7-9 bulan.

i. Ibu melahirkan harus ditolong oleh tenaga kesehatan.

j. Ibu nifas harus melakukan pemeriksaan dan mendapat pelayanan KB pasca persalinan setidaknya 3 kali pada pertama, keempat, dan keenam setelah melahirkan.

k. Anak penyandang disabilitas dapat memeriksakan kesehatan di dokter spesialis atau psikolog sesuai jenis kecacatan.

\section{Pendidikan}

Peserta PKH diwajibkan memenuhi persyaratan pendidikan dan mengikuti kehadiran di satuan pendidikan atau rumah singgah minimal 85\% dari hari sekolah dalam sebulan selama tahun ajaran berlangsung dengan catatan sebagai berikut:

a. Anak usia 7-15 tahun diwajibkan untuk terdaftar pada lembaga pendidikan dasar (SD/MI atau SMP/MTs). Apabila anak berusia 5-6 tahun sudah masuk sekolah dasar, maka yang bersangkutan dikenakan persyaratan pendidikan.

b. Anak penyandang disabilitas yang masih mampu mengikuti pendidikan reguler dapat mengikuti pendidikan SD/MI atau SMP/MTs, sedangkan yang tidak mampu dapat mengikuti pendidikan non reguler yaitu SDLB atau SMLB.

c. Anak usia 15-18 tahun dan belum menyelesaikan pendidikan dasar, maka diwajibkan didaftarkan ke lembaga pendidikan reguler atau non reguler (SD/MI dan SMP/MTs atau Paket A dan Paket B).

d. Anak yang bekerja atau telah meninggalkan sekolah cukup lama, maka harus mengikuti program remedial yaitu mempersiapkannya kembali ke lembaga pendidikan. Program remedial adalah layanan rumah singgah yang dilaksanakan Kementerian Sosial untuk anak jalanan dan Kemenakertrans untuk anak pekerja.

Apabila kedua persyaratan diatas (kesehatan dan pendidikan) dilaksanakan secara konsisten oleh peserta $\mathrm{PKH}$, maka mereka akan memperoleh bantuan secara teratur. Apabila tidak memenuhi kewajiban, maka jumlah bantuan yang diterima akan dikurangi bahkan dapat dihentikan.

Berdasarkan observasi dan wawancara yang dilakukan pada keluarga penerima bantuan tunai bersyarat di Desa Padang Seurahet, bahwasanya para informan mengatakan sangat bermanfaat dan mensejahterakan keluarga mereka. Semenjak pemerintah meluncurkan program PKH pada tahun 2007, ada beberapa perubahan yang dirasakan oleh keluarga penerima $\mathrm{PKH}$, seperti dana tunai yang diberikan sangat membantu memenuhi kebutuhan keluarga yang selama ini belum sepenuhnya mencukupi kebutuhan mereka, dapat membeli keperluan dan perlengkapan anak sekolah, dan mampu memberikan les belajar tambahan untuk anak. Pernyataan tersebut didukung oleh hasil wawancara dengan informan NA dan informan AM yang mengemukakan bahwa:

"Selama keluarga saya ditetapkan sebagai penerima bantuan PKH dari pemerintah, ada perubahan sebelum dan sesudah mendapatkan bantuan ini, contohnya setelah mendapatkan bantuan PKH sangat membantu memenuhi kebutuhan keluarga, apalagi pekerjaan suami sebagai nelayan, terkadang penghasilan tidak tetap, sangat bergantung pada kondisi laut dan cuaca. Ya ketika tidak ada penghasilan dari itu, keluarga ada harapan dari uang bantuan untuk mencukupi kebutuhan di rumah (Wawancara, 20 Desember 2020)"

Hasil wawancara dengan informan tersebut menunjukkan adanya perubahan yang dialami oleh keluarga penerima manfaat PKH. Hal ini dirasakan pada perbedaan kondisi keluarga sebelum pemerintah meluncurkan program PKH dan sesudah program ini terealisasikan di dalam masyarakat. Para Informan sangat berterimakasih kepada pemerintah telah turut memperhatikan keluarga miskin dan mensejahterakan keluarga mereka, dan merubah kondisi ekonomi keluarga ke arah yang lebih baik dari sebelumnya.

Berbicara tentang perubahan sosial yang dialami oleh keluarga penerima bantuan tunai Program Keluarga Harapan, perubahan sosial yang dialami dilihat dari 3 (tiga) dimensi yaitu melihat waktu yang berbeda dengan istilah kata dulu, sekarang, dan masa akan datang atau masa depan (Indraddin \& Irwan, 2016: 3).

Menurut Samuel Koenig (dalam buku Muin, 2007: 3-4), perubahan sosial menunjuk pada modifikasi-modifikasi yang terjadi dalam pola-pola kehidupan manusia. Modifikasi tersebut dapat terjadi karena sebab-sebab internal dan eksternal. Perubahan tersebut terealisasi disebabkan karena kebijakan PKH yang diimplementasi pemerintah.

Berdasarkan hasil di lapangan menunjukkan bahwa sebelum PKH direalisasikan, mereka sangat terbatas ekonomi dalam pemenuhan kebutuhan keluarga, yang pekerjaan suami mayoritas nelayan, sehingga ketika cuaca tidak mendukung, maka penghasilan yang diperoleh sangat sedikit atau bahkan tidak ada, sehingga mereka mengambil pinjaman kepada tengkulak untuk kebutuhan rumah tangga. Tetapi sekarang dikondisi seperti ini, bagi keluarga penerima PKH ada harapan yang dinantikan di dana PKH yang cair untuk memenuhi kebutuhan konsumsi keluarga, mensejahterakan keluarga informan, dan adanya perubahan semenjak ditetapkan sebagai penerima manfaat Program Keluarga Harapan.

Program Keluarga Harapan yang dijalankan telah membantu masyarakat miskin peserta PKH untuk memenuhi kebutuhan dasarnya, sehingga dapat meringankan beban pengeluaran yang ditanggung mereka. Hal tersebut menyebabkan sebagian besar masyarakat penerima dapat membelanjakan pendapatannya untuk keperluan rumah tangga (Fajriati, 2020; Senduk, 2021). Dengan artian implementasi program $\mathrm{PKH}$ berpengaruh positif terhadap kesejahteraan masyarakat (Mawarni, 2019: 10-11).

PKH juga berdampak dalam meningkatkan taraf pendidikan atau dapat membiayai pendidikan, meningkatkan partisipasi sekolah, dan meningkatnya kualitas kesehatan, disebabkan pendidikan dan kesehatan merupakan syarat bagi 
penerima manfaat program untuk berpartipasi pada kedua aspek tersebut (Hasna, 2019; Setyawardani, 2020).

\section{Penurunan Angka Kemiskinan di Aceh}

Program Keluarga Harapan bertujuan untuk menanggulangi kemiskinan dan tujuan tersebut dapat terealisasi di dalam kehidupan masyarakat. Sebagaimana data Badan Pusat Statistik (BPS) terkait profil kemiskinan di Aceh. Dalam data tersebut, BPS mencatat terjadi penurunan penduduk miskin secara persentase pada Maret 2020. Untuk mendukung pernyataan ini, penulis menyajikan pada Tabel 1 . Persentase Penduduk Miskin Menurut Provinsi, September 2019 dan Maret 2020 (\%).

Tabel 1. Persentase Penduduk Miskin Menurut Provinsi, September 2019 dan Maret 2020 (\%)

\begin{tabular}{|c|c|c|}
\hline Provinsi & September 2019 & Maret 2020 \\
\hline Aceh & 15,01 & 14,99 \\
\hline Sumatera Utara & 8,63 & 8,75 \\
\hline Riau & 6,90 & 6,82 \\
\hline Jambi & 7,51 & 7,58 \\
\hline Sumatera Selatan & 12,56 & 12,66 \\
\hline Bengkulu & 14,91 & 15,03 \\
\hline Lampung & 12,30 & 12,34 \\
\hline Kepulauan Bangka & 4,50 & 4,53 \\
\hline Belitung & & \\
\hline Kepulauan Riau & 5,80 & 5,92 \\
\hline DKI Jakarta & 3,42 & 4,53 \\
\hline Jawa Barat & 6,82 & 7,88 \\
\hline Jawa Tengah & 10,58 & 11,41 \\
\hline DI Yogyakarta & 11,44 & 12,28 \\
\hline Jawa Timur & 10,20 & 11,09 \\
\hline Banten & 4,94 & 5,92 \\
\hline Bali & 3,61 & 3,78 \\
\hline Nusa Tenggara Barat & 13,88 & 13,97 \\
\hline Nusa Tenggara Timur & 20,62 & 20,90 \\
\hline Kalimantan Barat & 7,28 & 7,17 \\
\hline Kalimantan Tengah & 4,81 & 4,82 \\
\hline Kalimantan Selatan & 4,47 & 4,38 \\
\hline Kalimantan Timur & 5,91 & 6,10 \\
\hline Kalimantan Utara & 6,49 & 6,80 \\
\hline Sulawesi Utara & 7,51 & 7,62 \\
\hline Sulawesi Selatan & 8,56 & 8,72 \\
\hline Sulawesi Tenggara & 11,04 & 11,00 \\
\hline Gorontalo & 15,31 & 15,22 \\
\hline Sulawesi Barat & 10,95 & 10,87 \\
\hline Maluku & 17,65 & 17,44 \\
\hline Maluku Utara & 6,91 & 6,78 \\
\hline Papua Barat & 21,51 & 21,37 \\
\hline Papua & 26,55 & 26,64 \\
\hline
\end{tabular}

Sumber: BPS Aceh

Data itu mencatat penduduk miskin di Aceh mengalami penurunan sebesar 0,02 persen. Artinya Aceh kini bukan lagi menjadi daerah termiskin di Pulau Sumatera. Dari data terbaru itu, BPS mencatat provinsi Bengkulu sebagai provinsi termiskin di Sumatera dengan persentase 15,03 persen. Sementara provinsi dengan peningkatan kemiskinan tertinggi adalah DKI Jakarta yaitu naik sebesar 1,1l persen.

Kepala BPS Aceh Ihsanurrijal dalam keterangannya mengatakan, persentase penduduk miskin Aceh pada Maret 2020 yaitu 14,99 persen atau turun 0,02 persen dibandingkan September 2019. Enam bulan lalu yaitu di bulan September persentase penduduk miskin yaitu 15,01 persen. Pada Maret 2019, penduduk miskin tercatat 819,44 ribu orang, sementara Maret 2020, tersisa 814,91 ribu orang.

Plt Gubernur Aceh Nova Iriansyah dalam keterangan yang disampaikan kepada Bappeda Aceh, Helvizar Ibrahim, berterimakasih kepada seluruh jajaran yang telah mendukung pemerintah dalam menekan angka kemiskinan di Aceh. Berbagai upaya terus dilakukan agar angka kemiskinan itu bisa dipangkas secara perlahan (Humas Aceh, 2020).

\section{Aceh Barat Miliki 19.648 Keluarga Miskin}

Dinas sosial Kabupaten Aceh Barat, Provinsi Aceh mencatat masih terdapat 19.648 keluarga golongan masyarakat fakir dan miskin di daerah ini. Itu diukur berdasarkan pendapatan warganya yang masih jauh dibawah Upah Minimum Provinsi (UMP) senilai 2,9 juta. Kabid Dayasos dan penanganan Fakir Miskin, T Remi Ilham Putra mengatakan jumlah penduduk miskin terbesar berada di kawasan pesisir yakni meliputi kecamatan Johan Pahlawan, Kecamatan Meureubo, Samatiga, dan Arongan Lambalek.

Mayoritas penduduk miskin Aceh Barat berada di kawasan pesisir, namun persebarannya juga merata di 12 kecamatan. Data ini sesuai dengan verifikasi di imput, Badan Pusat Statistik (BPS) dan menjadi rujukan nasional. Ada dua permukiman yang tercatat sebagai tempat tinggal warga miskin, pertama kawasan pesisir, kedua pedesaan, namun kriteria fakir dan miskin masyarakat tersebut semuanya serupa, dengan pendapatan rata-rata Rp 700 ribu per bulan. Dalam upaya penanganan dan pengentasan kemiskinan, Dinas Sosial Aceh Barat terus melaksanakan beberapa program pemberdayaan ekonomi, sosial, dan penyaluran bantuan untuk meningkatkan taraf hidup keluarga fakir maupun keluarga miskin (Firmansyah, 2019).

\section{Angka Kemiskinan Aceh Barat Menurun}

Data Badan Pusat Statistik (BPS) Aceh Barat dalam angka yang diterbitkan April 2020 menulis, rata-rata penurunan angka kemiskinan di Bumi Teuku Umar, bergerak sekitar satu persen lebih. Rektor Universitas Teuku Umar (UTU) Meulaboh, Prof. Jasman J Ma'aruf yang diminta media ini pendapatnya mengatakan jika penurunan angka kemiskinan satu persen, itu sudah bagus.

Sementara itu BPS Aceh Barat menyebutkan, presentase penduduk miskin Aceh Barat tahun 2017 sebesar 20,28 persen. Tahun 2018 sebesar 19,31 persen, dan tahun 2019 sebesar 18,79 persen. Sedangkan jumlah penduduk miskin tahun 2017 sebanyak 40.720 orang, tahun 2018 sebanyak 39.562 orang, dan tahun 2019 sebanyak 39.290 orang (Saidi, 2020).

Penurunan angka kemiskinan tersebut merupakan suatu perubahan yang terjadi dalam masyarakat yang disebabkan oleh hadirnya program-program pengentasan kemiskinan, yaitu salah satu PKH. Menurut Indraddin dan Irwan (2016: 2), perubahan sosial yang terjadi dalam masyarakat disebabkan adanya faktor pendorong baik dari dalam maupun faktor dari luar. Perubahan sosial yang terjadi disebabkan faktor eksternal yaitu karena Program Keluarga Harapan dari pemerintah untuk 
masyarakat miskin, dan program PKH merupakan bentuk perubahan yang secara sadar direncanakan oleh pemerintah demi kesejahteraan keluarga miskin dan sebagai strategi penanggulangan kemiskinan.

\section{KESIMPULAN}

Program Keluarga Harapan (PKH) adalah program bantuan tunai bersyarat yang diluncurkan oleh pemerintah untuk masyarakat miskin. Persyaratan yang diajukan bagi penerima $\mathrm{PKH}$ yaitu dalam pendidikan (anak penerima $\mathrm{PKH}$ harus terdaftar di lembaga sekolah dan sedang melanjutkan pendidikan), dan kesehatan (bagi ibu hamil dan balita harus mengikuti pelayanan kesehatan, seperti posyandu).

Program Keluarga Harapan ini sebagai partisipasi dan kebijakan pemerintah untuk mengentaskan dan menurunkan angka kemiskinan. Mengingat bahwa Indonesia masih negara berkembang sehingga masalah ekonomi masih meraja lela. Dengan demikian, pemerintah memberikan kontribusi nya yang tertuang dalam program berbasis rumah tangga yaitu Program Keluarga Harapan di Indonesia, khususnya Aceh.

Semenjak pemerintah meluncurkan program bantuan sosial ini, secara langsung berdampak terhadap penurunan angka kemiskinan di Aceh, persentase angka kemiskinan turun menjadi 0,02\%, dan ini sebagai langkah awal yang bagus dalam menurunkan angka kemiskinan di Aceh. Kemudian PKH dapat mensejahterakan keluarga penerima manfaat di Desa Padang Seurahet. Merujuk pada hasil lapangan, mengemukakan bahwa keluarga penerima bantuan mengalami perubahan dalam keluarga nya, yaitu dapat membantu pemenuhan konsumsi dan kebutuhan keluarga, yang dana tunai tersebut mayoritas digunakan untuk ekonomi keluarga.

\section{REFERENSI}

Aceh, Humas. (2020, Juli 15). Data BPS: Aceh Bukan Lagi Daerah Termiskin

Sumatera. Https://humas.acehprov.go.id.

Cermati. (2016). Program Keluarga Harapan, apa manfaat yang ditawarkan. Https://www.cermati.com.

Cahyono, Tri. (2018). Gerak Langkah Program Keluarga Harapan: Kontribusi PKH Terhadap Kesejahteraan Keluarga Penerima Manfaat. Jurnal penelitian kesejahteraan sosial, 17 (4). Https://ejournal.kemsos.go.id.

Firmansyah, Aidil. (2019, Maret 20). Aceh Barat Miliki 19.648 Keluarga Miskin. Https://modusaceh.co.id.

Fajriati, Nurul Irtiah. (2020). Analisis pengaruh PKH dalam peningkatan kesejahteraan masyarakat miskin. Jurnal Najaha Iqtishod, 1 (1), 48-49. Https://onlinejournal.unja.ac.id.

Hasna, Nurma Mustika. (2019). Analisis Dampak Pemberian Bantuan Program Keluarga Harapan Terhadap Kesejahteraan Masyarakat. Jurnal Pancasila dan Kewarganegaraan, 7 (2), 8-9. Https://e-journal.unipma.ac.id

Indraddin \& Irwan. (2016). Strategi dan Perubahan Sosial. Yogyakarta: Deepublish.

Jayanti, Winda. (2018). Pengaruh Program Keluarga Harapan Terhadap Kesejahteraan Keluarga Di Desa Pasar $X$ Kecamatan Kutalimbaru Kabupaten DeliSerdang (Skripsi Kesejahteraan Sosial, Universitas Sumatera Utara, Medan). Https://repositori.usu.ac.id.

Muin, Idianto. (2007). Sosiologi. Jakarta: Erlangga.
Mawarni, Kahfi Septian. (2019). Pengaruh Implementasi Program Keluarga Harapan Terhadap Kesejahteraan Masyarakat Oleh Pendamping PKH di Desa Ciomas Kecamatan Panjalu Kabupaten Ciamis. Jurnal Ilmiah Ilmu Administrasi Negara, 6 (3), 10-11. Https://jurnal.unigal.ac.id.

Pancawangi. (2019). Apa, Tujuan, dan Siapa Penerima Manfaat Program Keluarga Harapan (PKH). Https://pancawangi.sideka.id.

Resi Prasasti. (2017). Yuk Mengenal Program Keluarga Harapan (PKH). Https://indonesiabaik.id.

Sztompka, Piotr. (2004). Sosiologi Perubahan Sosial. Jakarta: Kencana.

Sugiyono. (2014). Memahami Penelitian Kualitatif. Bandung: Alfabeta.

Saidi, Juli. (2020, Mei 8). Angka Kemiskinan Aceh Barat Turun. Https://modusaceh.co.id.

Setyawardani, Diyah Tri Rezki. (2020). Dampak Bantuan PKH Terhadap Masyarakat Miskin Di Kelurahan Bumi Nyiur Kecamatan Wanea Kota Manado. Jurnal Holistik,

13

(2), 13-14. Https://ejournal.unsrat.ac.id.

Senduk, Nikita Vidiana. (2021). Dampak Pelaksanaan PKH Dalam Meningkatkan Kesejahteraan Masyarakat Di Kelurahan Bumi Beringin Kecamatan Wenang Kota Manado. Jurnal Administrasi Publik, 7 (101), 46-47. Https://ejournal.unsrat.ac.id.

Utomo, Dedi. (2012). Pelaksanaan Program Keluarga Harapan Dalam Meningkatkan Kualitas Hidup Rumah Tangga Miskin. Jurnal administrasi publik, 2 (1), 29-34. Https://media.neliti.com.

Virgoreta, Dyah Ayu. (2014). Implementasi Program Keluarga Harapan (PKH) Dalam Upaya Meningkatkan Kesejahteraan Masyarakat. Jurnal Administrasi Publik, 2 (12),1-6. Https://media.neliti.com. 